\title{
Removal of 2,4-D herbicide from aqueous solution by aminosilane- grafted mesoporous carbons
}

\author{
Joanna Goscianska ${ }^{1}$ (D) Anna Olejnik ${ }^{1}$
}

Received: 15 December 2018 / Revised: 13 January 2019 / Accepted: 14 January 2019 / Published online: 24 January 2019

(c) The Author(s) 2019, corrected publication 2019

\begin{abstract}
2,4-Dichlorophenoxyacetic acid (2,4-D) is the most commonly used herbicide in plant protection products. 2,4-D is poorly biodegradable and it is often found in aquatic environment. The development of an effective way to reduce the amount of this toxic contaminant from aqueous solution became an urgent issue. Therefore, in this study series of aminosilane-grafted mesoporous carbons were synthesized, characterized and then applied as adsorbents for 2,4-D. The impact of various factors such as the contact time (0-360 min) of herbicide with adsorbents, $\mathrm{pH}(2-11)$, temperature $\left(25,45,60{ }^{\circ} \mathrm{C}\right)$ and initial concentration $(6.25-150 \mathrm{mg} / \mathrm{l})$ of the 2,4-D on the sorption capacity of materials was analyzed. The results proved that functionalization of mesoporous carbons with aminosilane increased the sorption capacity $\left(q_{e}=142-191 \mathrm{mg} / \mathrm{g}\right)$ towards herbicide compared to pristine material $\left(q_{e}=109 \mathrm{mg} / \mathrm{g}\right)$. The functional groups presented on the surface of materials enhanced the interaction between mesoporous carbons and herbicide. The most effective adsorbent for 2,4-D was the material that had the highest amount of basic groups on the surface $(2.79 \mathrm{mmol} / \mathrm{g})$ of all samples tested $(0.06-0.52 \mathrm{mmol} / \mathrm{g})$. For all studied materials the Langmuir model was the most suitable to describe the isotherms of 2,4-D adsorption $\left(R^{2}=0.999\right)$. While the kinetics of herbicide adsorption on the functionalized mesoporous carbons were best fitted to the pseudo-second-order model. The presented study proved that the aminosilane-grafted mesoporous carbons could be promising adsorbents for effective removal of 2,4-D from aqueous environment.
\end{abstract}

Keywords 2,4-Dichlorophenoxyacetic acid · Pesticide $\cdot$ Adsorption $\cdot$ Functionalization of mesoporous carbons $\cdot$ Hard template method $\cdot 3$-Aminopropyltriethoxysilane

\section{Introduction}

Large amounts of synthetic organic pollutants including pesticides, herbicides, dyes and pharmaceuticals are daily released into many types of wastewaters and enter into natural water channels to be accumulated in the aquatic environment (Agarwal et al. 2016; Bartczak et al. 2016; Goscianska et al. 2017). These contaminations arise from urban, industrial and agricultural human activities. Among numerous herbicides, 2,4-dichlorophenoxyacetic acid $(2,4-\mathrm{D})$ is the most popular component of plant protection products. 2,4-D is commonly applied in agriculture due to its low cost and good selectivity (Liu et al. 2016). It stimulates the cells to uncontrolled growth that

Joanna Goscianska

asiagosc@amu.edu.pl

1 Faculty of Chemistry, Adam Mickiewicz University in Poznań, Umultowska 89B, 61-614 Poznan, Poland leads to the plant's death in the last stage (Bartczak et al. 2016). 2,4-dichlorophenoxyacetic acid is widely applied in the cultivation of soya, maize, sugar cane and wheat. It is extensively used to control the growth of broad-leaf weeds in grain and cereal crops. However, this compound is poorly biodegradable therefore it is often found in water reservoir all over the world (Aksu and Kabasakal 2004). It has been proved that this pesticide could not only pose a threat to aquatic life but also could be toxic to animals and humans (Bus and Hammond 2007). It was reported that 2,4-D could have a negative influence on the proper functioning of the human beings. The oral exposure of humans to 2,4-D may induce headache, diarrhea and confusion (Reigart and Roberts 1999). Moreover, this compound is classified as carcinogenic, mutagenic and can have negative effect on the central nervous system and kidneys (Bradberry et al. 2004). Furthermore, the longterm exposure to 2,4-D may cause moderate and serious skin irritation (Njoku and Hameed 2011). Therefore, the 
development of an effective way to reduce the amount of 2,4-D in environment became an urgent and important issue. So far different methods have been used to remove herbicides from aqueous solutions such as coagulation, photodegradation, sedimentation, flotation, filtration and chemical oxidation (Ormad et al. 2008; Tsogas et al. 2006; Broseus et al. 2009). However, adsorption has been found to be the most competitive method due to its low cost, mild operation conditions, flexibility and ease of operation (Ova and Ovex 2013). It is assumed that this process could be a promising alternative to conventional water treatment systems. So far 2,4-D was adsorbed on different types of materials such as activated carbon (Njoku et al. 2015), modified silica gel (Koner et al. 2013), polystyrene beads (Olejnik et al. 2018a, b), chitosan (Harmoudi et al. 2014), bentonite ( $\mathrm{Li}$ et al. 2009), magnetic graphene (Liu et al. 2016) and graphene oxide coated with porous iron oxide ribbons (Nethaji and Sivasamy 2017). However, the application of these materials on a larger scale has some drawbacks. On one hand the production and regeneration costs of activated carbons are very high. On the other hand the adsorption capacity of other sorption materials was not satisfactory enough. Therefore, there is still demand to search for new efficient adsorbent for 2,4-D. The recent progress in obtaining novel functionalized nanomaterials such mesoporous carbons has open new path for their applications (Barczak et al. 2015; Goscianska et al. 2016a, b, 2017; Yang et al. 2018). In the present study, 3-aminopropyltriethoxysilane-functionalized mesoporous carbons were applied for the first time as adsorbents of 2,4-D (Fig. 1). The effect of the contact time of adsorbate with adsorbents, $\mathrm{pH}$, initial concentration of the 2,4-D anionic herbicide solution and temperature on the sorption capacity of materials was established. The experimental data obtained from the equilibrium studies were fitted to Langmuir and Freundlich adsorption models. In addition, kinetic studies were also carried out to determine both adsorption and desorption processes.

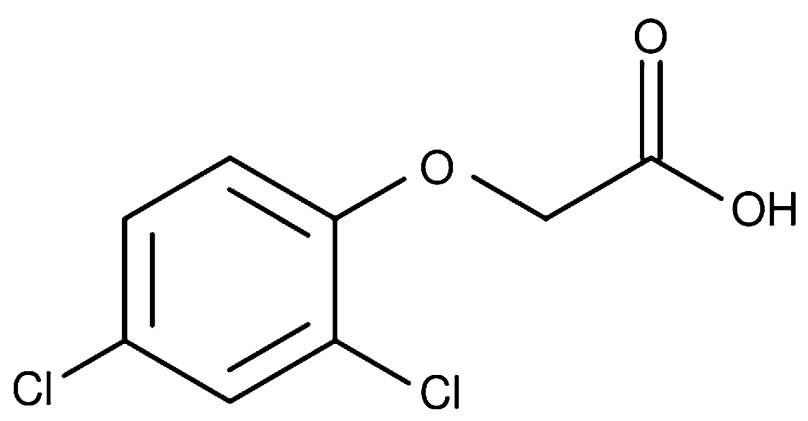

Fig. 1 Structure of 2,4-dichlorophenoxyacetic acid

\section{Experimental}

\subsection{Adsorbent preparation}

\subsubsection{Synthesis of KIT- 6 template}

Ordered mesoporous silica KIT-6 of cubic structure was hydrothermally synthesized according to the procedure described previously (Goscianska et al. 2013). Briefly, $4 \mathrm{~g}$ of Pluronic P123 triblock copolymer $\left(\mathrm{EO}_{20} \mathrm{PO}_{70} \mathrm{EO}_{20}\right.$, Aldrich) was dissolved in a mixture of $144 \mathrm{~g}$ of distilled water and $7.9 \mathrm{~g}$ of hydrochloric acid (35-38\%, made by POCh), and stirred at $35^{\circ} \mathrm{C}$ for $2 \mathrm{~h}$. Then $4 \mathrm{ml}$ of butan-1-ol (POCh) was added. After $1 \mathrm{~h}$ of stirring, $8.6 \mathrm{ml}$ of tetraethyl orthosilicate (98 wt\%, Sigma-Aldrich) was introduced dropwise to the solution, which was maintained at $35^{\circ} \mathrm{C}$ for further $24 \mathrm{~h}$ under stirring. The resulting sol-gel slurries were hydrothermally aged for $24 \mathrm{~h}$ at $100{ }^{\circ} \mathrm{C}$. Next, the solid product was filtered without washing and dried at $100{ }^{\circ} \mathrm{C}$ for $24 \mathrm{~h}$ in an air oven. Finally, the sample was calcined at $550{ }^{\circ} \mathrm{C}$ in air to remove the triblock copolymer and to obtain KIT- 6 silica material.

\subsubsection{Synthesis of ordered mesoporous carbon}

In a typical synthesis of carbon material $\mathrm{C}_{\mathrm{KIT}-6}, 1 \mathrm{~g}$ of silica material KIT- 6 was immersed in a solution of $1.25 \mathrm{~g}$ of sucrose (Aldrich), $0.14 \mathrm{~g}$ of concentrated $\mathrm{H}_{2} \mathrm{SO}_{4}(95 \%$, Chempur) and $5 \mathrm{ml}$ of distilled water. The mixture was heated for $6 \mathrm{~h}$ at $100{ }^{\circ} \mathrm{C}$ and then the temperature was increased to $160^{\circ} \mathrm{C}$ for another $6 \mathrm{~h}$. The resulting solid was again immersed into a solution of $0.8 \mathrm{~g}$ of sucrose, $0.09 \mathrm{~g}$ of $\mathrm{H}_{2} \mathrm{SO}_{4}$ and $5 \mathrm{ml}$ of water. The heating process was repeated again by drying the mixture at $100{ }^{\circ} \mathrm{C}$ and $160{ }^{\circ} \mathrm{C}$ for $6 \mathrm{~h}$. The carbonization was completed by pyrolysis with heating to typically $900{ }^{\circ} \mathrm{C}$ for $6 \mathrm{~h}$ in argon atmosphere. After carbonization, the template-containing carbon was washed with $5 \mathrm{wt} \%$ hydrofluoric acid (Sigma-Aldrich) twice at room temperature to remove the silica template. The template-free product was washed with water and then with ethanol before drying at $100{ }^{\circ} \mathrm{C}$ overnight.

\subsubsection{Functionalization of mesoporous carbon}

The main goal of the modification was the creation of basic groups on the surface of the pristine mesoporous carbon. The functionalization of $\mathrm{C}_{\mathrm{KIT}-6}$ material was performed in two steps:

2.1.3.1 Oxidation For a typical treatment, $0.5 \mathrm{~g}$ of $\mathrm{C}_{\mathrm{KIT}-6}$ sample was put into the reactor filled with $30 \mathrm{ml}$ of $1 \mathrm{~mol} / \mathrm{l}$ 
acidic ammonium persulfate solution and stirred for $6 \mathrm{~h}$ at $60{ }^{\circ} \mathrm{C}$. After that, the mixture was filtered and washed with distilled water and ethanol. The material obtained was dried at $100{ }^{\circ} \mathrm{C}$ overnight.

\subsubsection{Grafting with 3-aminopropyltriethoxysilane} (APTES) At first 1.2, 3 or $6 \mathrm{ml}$ of APTES were stirred for $30 \mathrm{~min}$ with $30 \mathrm{ml}$ of methanol (POCh) in three roundbottomed flasks and then $3 \mathrm{~g}$ portions of oxidized carbon material was introduced. The mixtures were stirred at $40{ }^{\circ} \mathrm{C}$ for $8 \mathrm{~h}$. In the next step, the grafted carbon materials were filtered, washed with methanol and dried at $100{ }^{\circ} \mathrm{C}$ overnight. Aminosilane-functionalized samples were labelled as $\mathrm{C}_{\mathrm{KIT}-6-\mathrm{A} 1}$ (material modified with $1.2 \mathrm{ml}$ of APTES), $\mathrm{C}_{\mathrm{KIT}-6-\mathrm{A} 2}$ (material modified with $3 \mathrm{ml}$ of APTES) and $\mathrm{C}_{\mathrm{KIT}-6-\mathrm{A} 3}$ (sample modified with $6 \mathrm{ml}$ of APTES).

\subsection{Adsorbent characterization}

Textural characteristic of the mesoporous carbons was performed with the use of a Quantachrome Autosorb IQ apparatus by nitrogen adsorption/desorption measurements at $-196{ }^{\circ} \mathrm{C}$. The Brunauer-Emmett-Teller (BET) method was employed for the determination of surface areas $\left(\mathrm{S}_{\mathrm{BET}}\right)$ of carbon materials. Micropore surface areas were found using the t-plot method, whereas the total pore volumes were obtained from the amount of $\mathrm{N}_{2}$ adsorbed at a relative pressure close to unity. The average pore size was estimated from the adsorption branch of isotherm using Barret-JoynerHalenda (BJH) method.

For TEM measurements, all adsorbents were deposited on a grid with a perforated carbon film and transferred to a JEOL 2000 electron microscope operating at $80 \mathrm{kV}$.

The content of oxygen functional groups on the surface of the aminosilane-grafted mesoporous carbons was determined by the Boehm method (Boehm 1994). The acidic surface functional groups were neutralized by $0.1 \mathrm{~mol} / \mathrm{l} \mathrm{solu}$ tion of sodium hydroxide, while the basic surface functional groups were neutralized by $0.1 \mathrm{~mol} / 1$ solution of hydrochloric acid. The excess of the reagent used was titrated with $0.1 \mathrm{~mol} / \mathrm{l}$ solution of $\mathrm{HCl}$ (upon neutralization with $\mathrm{NaOH}$ solution) or $0.1 \mathrm{~mol} / 1$ solution of $\mathrm{NaOH}$ (upon neutralization with $\mathrm{HCl}$ solution) against methyl orange as an indicator.

\subsection{Adsorption studies}

For each adsorption test, $20 \mathrm{mg}$ of mesoporous carbon was flooded with $50 \mathrm{ml}$ of earlier prepared 2,4-D solutions of different concentrations from the range $6.25-150 \mathrm{mg} / \mathrm{l}$. The flooded materials were continuously stirred in the temperature-controlled orbital shaker (KS 4000i control, IKA, Germany) at a fixed shaking rate of $250 \mathrm{rpm}$ over a given period of time. Then the samples were filtered off and the solid phase was separated from the liquid. The absorbance of the filtrate was measured by using Agilent Cary $60 \mathrm{UV}-\mathrm{Vis}$ spectrophotometer (at the wavelength of $282 \mathrm{~nm}$ ).

The amount of the 2,4-D anionic herbicide adsorbed on a given mesoporous carbon $\left(q_{e}\right)$ expressed in $(\mathrm{mg} / \mathrm{g})$ was calculated from formula (1):

$q_{e}=\frac{\left(C_{0}-C_{e}\right) \cdot V}{m}$

where $C_{0}$ is the initial concentration of the 2,4-D (mg/l), $C_{e}$ is the 2,4-D herbicide concentration after adsorption $(\mathrm{mg} / \mathrm{l})$, $V$ is the volume of herbicide solution (l), $m$ is the mass of mesoporous carbon material $(\mathrm{g})$.

The effect of adsorption parameters such as the contact time of adsorbate-adsorbent (0-360 $\mathrm{min}), \mathrm{pH}(2-11)$, the initial herbicide concentration $(6.25-150 \mathrm{mg} / \mathrm{l})$ and adsorption temperature $\left(25,45,60^{\circ} \mathrm{C}\right)$ on the sorption capacity of the materials obtained was investigated in details.

\subsection{Desorption studies}

For desorption tests, 2,4-D was first adsorbed onto mesoporous carbons by a solvent evaporation technique to obtain the same initial quantity of herbicide in all materials. For this purpose, $25 \mathrm{mg}$ of carbon materials was added to $5 \mathrm{ml}$ of an aqueous solution of 2,4-D with concentration of $1 \mathrm{mg} / \mathrm{ml}$. The adsorption procedure was carried out for $24 \mathrm{~h}$, with stirring. Afterwards the solvent was evaporated and the samples loaded with herbicide were dried for $24 \mathrm{~h}$ at $100^{\circ} \mathrm{C}$. The desorption was conducted for $24 \mathrm{~h}$ in distilled water maintained at RT. The desorption progress was monitored every 30 min during the first $3 \mathrm{~h}$. Next the samples were withdrawn every hour up to $6 \mathrm{~h}$. The last measurement was performed after $24 \mathrm{~h}$. The concentration of 2,4-D desorbed was measured at $282 \mathrm{~nm}$ with the use of Agilent Cary 60 $\mathrm{UV}-\mathrm{V}$ is spectrophotometer.

\subsection{Desorption kinetics}

The desorption data were fitted with five different kinetics models such zero order (\% 2,4-D desorbed vs time), first order (log of $\%$ 2,4-D remaining vs time), Higuchi model (\% 2,4-D desorbed vs square root of time), Hixson-Crowell model (cube root of $\%$ of 2,4-D remaining vs time) and Korsmeyer-Peppas model (log of \% 2,4-D desorbed vs log time) in which $n$ value describes the desorption mechanism of 2,4-D using the following criteria:

- $\mathrm{n}<0.5(0.45)$ —quasi-Fickian diffusion,

- $\mathrm{n}=0.5(0.45)$-diffusion mechanism,

- $0.5<\mathrm{n}<1-$ non Fickian diffusion,

- $\mathrm{n}=1$ (0.89)—case II transport (zero order), 
- $\mathrm{n}>1(0.89)$ - super case II transport (Goscianska et al. 2016a, b; Sahoo et al. 2012; Dash et al. 2010; Olejnik et al. 2018a, b).

\section{Results and discussion}

\subsection{Characterization of adsorbents}

Structural and textural characterization of the aminosilanegrafted mesoporous carbons applied in this work as adsorbents of 2,4-D have already been published (Goscianska and Olejnik 2018) and therefore it will be only briefly recalled here.

The porous properties of materials were analyzed by $\mathrm{N}_{2}$ adsorption-desorption measurements and are depicted in Fig. 2. These data indicate that pristine mesoporous carbon exhibits the best developed surface area of $834 \mathrm{~m}^{2} / \mathrm{g}$ and large pore volume of $1.09 \mathrm{~cm}^{3} / \mathrm{g}$ with the contribution from micropores of $170 \mathrm{~m}^{2} / \mathrm{g}$ and $0.08 \mathrm{~cm}^{3} / \mathrm{g}$. It was observed that the process of functionalization of the $\mathrm{C}_{\mathrm{KIT}-6}$ material with 3-aminopropyltriethoxysilane strongly affected its textural parameters. As it can be seen the specific surface area of car-

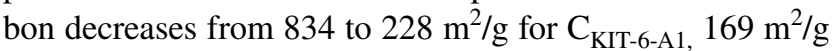
for $\mathrm{C}_{\mathrm{KIT}-6-\mathrm{A} 2}$ and $71 \mathrm{~m}^{2} / \mathrm{g}$ for $\mathrm{C}_{\mathrm{KIT}-6-\mathrm{A} 3}$. The total pore volumes decline gradually in the same order. The changes in the carbon
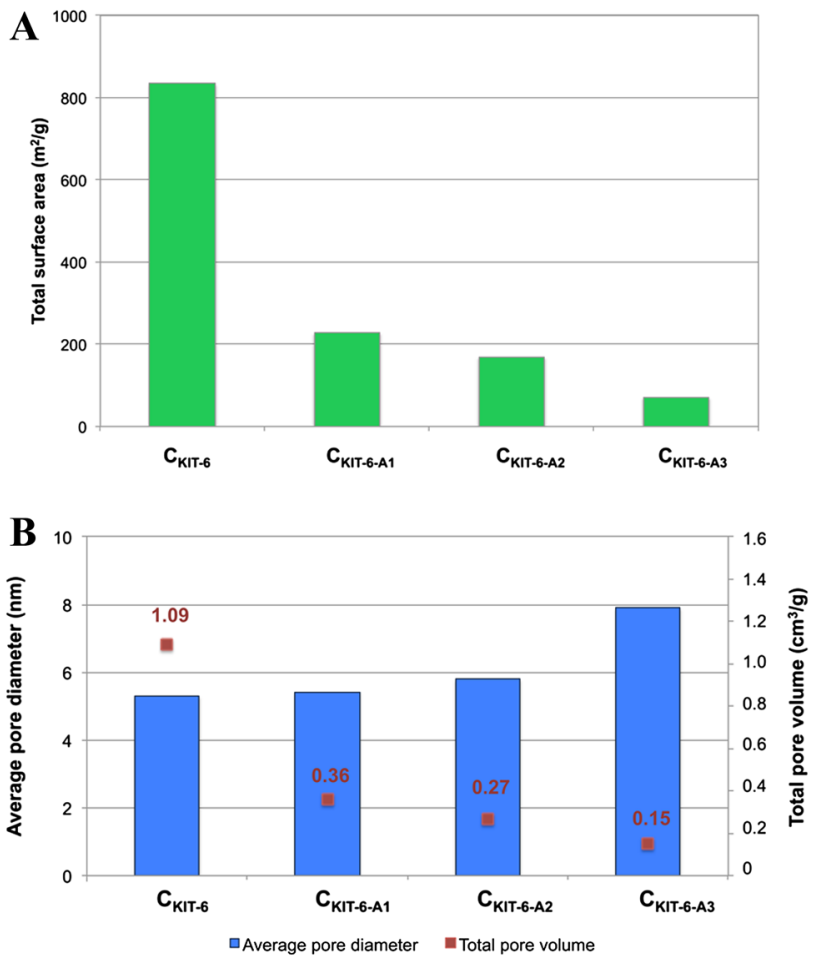

Fig. 2 Textural parameters of mesoporous carbons: A specific surface areas, $\mathbf{B}$ average pore diameters and total pore volumes texture are related to the anchoring of organic functional groups in the material pores. Moreover, the samples $\mathrm{C}_{\mathrm{KIT}-6-\mathrm{A} 1 \text {, }}$ $\mathrm{C}_{\mathrm{KIT}-6-\mathrm{A} 2}$ and $\mathrm{C}_{\mathrm{KIT}-6-\mathrm{A} 3}$ are also characterized by a greater mean pore size than $\mathrm{C}_{\mathrm{KIT}-6}$. It can be concluded that the functionalization of the carbon surface with APTES happens at the micropore/mesopore openings, due to the high potential field in small pores and the easy susceptibility of attachment at the pore openings.

A series of aminosilane-grafted mesoporous carbons were investigated by transmission electron microscopy to observe ordering of their structure. TEM images of the samples synthesized are presented in Fig. 3. The pristine mesoporous carbon shows a highly ordered cubic mesostructure, an inverse replica of KIT-6 silica. TEM images also suggest that pore structure is not destroyed after functionalization of $\mathrm{C}_{\mathrm{KIT}-6}$ with APTES, however, some structural changes are observed. The material grafted with the highest amount of aminosilane $\left(\mathrm{C}_{\mathrm{KIT}-6-\mathrm{A} 3}\right)$ exhibits slightly poorer structure ordering than other samples.

The content of oxygen functional groups on the surface of materials was determined by Boehm titration and the results are presented in Fig. 4. As can be observed, $\mathrm{C}_{\mathrm{KIT}-6-\mathrm{A} 1 \text {, }}$ $\mathrm{C}_{\mathrm{KIT}-6-\mathrm{A} 2}$ and $\mathrm{C}_{\mathrm{KIT}-6-\mathrm{A} 3}$ samples are characterized by higher number of oxygen functional groups of basic character than pure mesoporous carbon. This indicates, on the one hand, the efficiency of functionalization, on the other hand, suggests differences in the nature of surface chemistry of the adsorbents. Moreover, the modification of $\mathrm{C}_{\mathrm{KIT}-6}$ sample with 3-aminopropyltriethoxysilane in the highest concentration leads to total disappearance of acidic groups.

\subsection{Adsorption studies}

The relations between the amount of the 2,4-D adsorbed $\left(q_{e}\right)$ and the contact time of the mesoporous carbons surface with herbicide solution are presented in Fig. 5. For the first 20 min of contact the process is very fast, which can be explained by a large number of free adsorption sites available for the 2,4-D molecules. At the next stage, from 30 to about $100 \mathrm{~min}$, adsorption is much slower because most of free adsorption sites on the surface of carbon materials have been occupied by herbicide molecules. After about $120 \mathrm{~min}$ the state of equilibrium is reached, (Fig. 5). After this time the value of $q_{e}$ shows no further increase.

Kinetics of 2,4-D herbicide adsorption onto aminosilanegrafted mesoporous carbons was characterized on the basis of comparison to two kinetic models. The Lagergren model of pseudo-first order kinetics is described by the following equation (Lagergren 1898):

$\ln \left(q_{e}-q_{t}\right)=\ln q_{e}-\frac{k_{1} t}{2.303}$

where $q_{e}$ is the amount of 2,4-D herbicide adsorbed at equilibrium $(\mathrm{mg} / \mathrm{g}), q_{t}$ is the amount of 2,4-D herbicide adsorbed 
Fig. 3 TEM images of $\mathrm{C}_{\mathrm{KIT}-6}$ (A), $\mathrm{C}_{\text {KIT-6-A1 }}(\mathbf{B}), \mathrm{C}_{\mathrm{KIT}-6-\mathrm{A} 2}(\mathbf{C})$, $\mathrm{C}_{\text {KIT-6-A3 }}(\mathbf{D})$
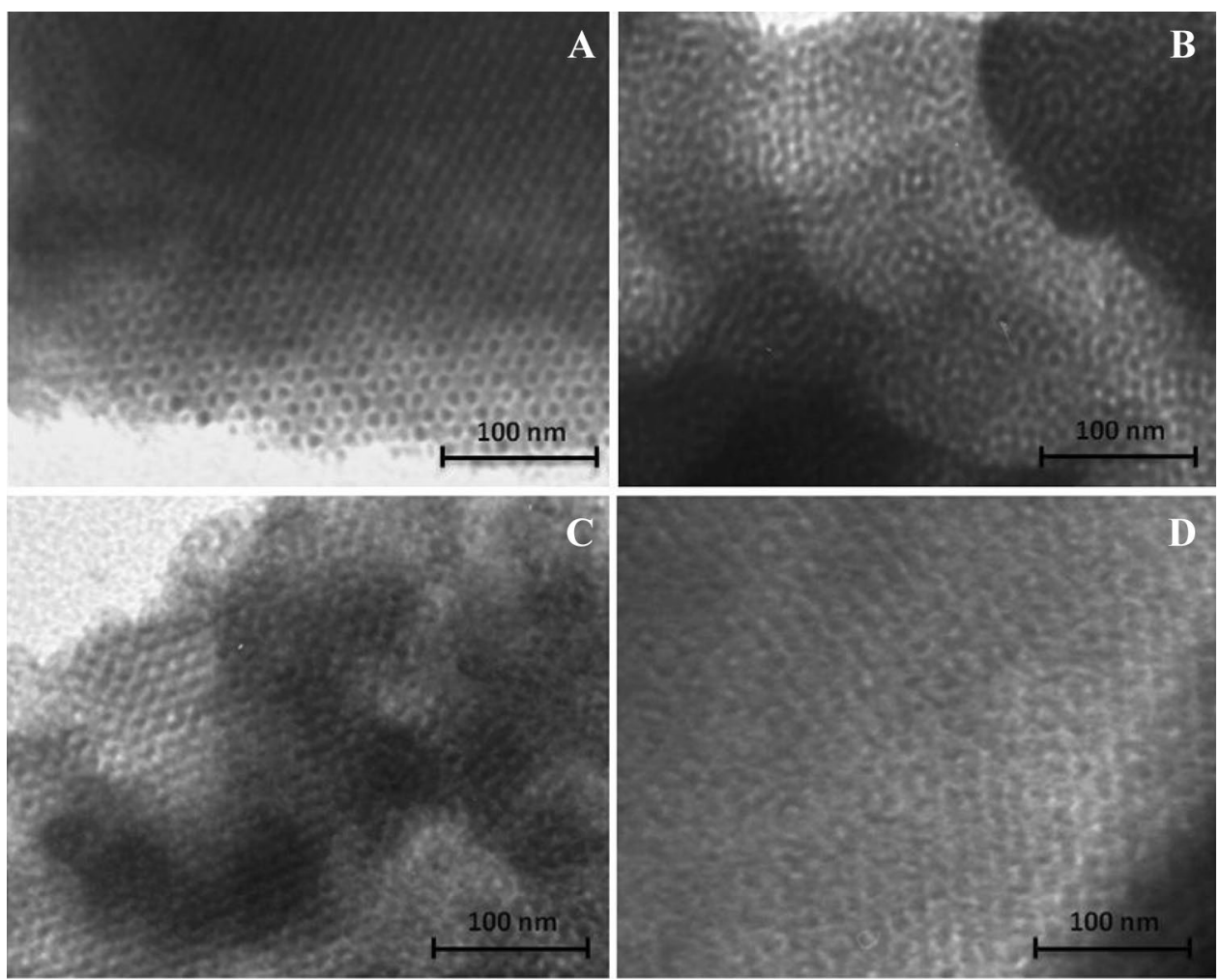

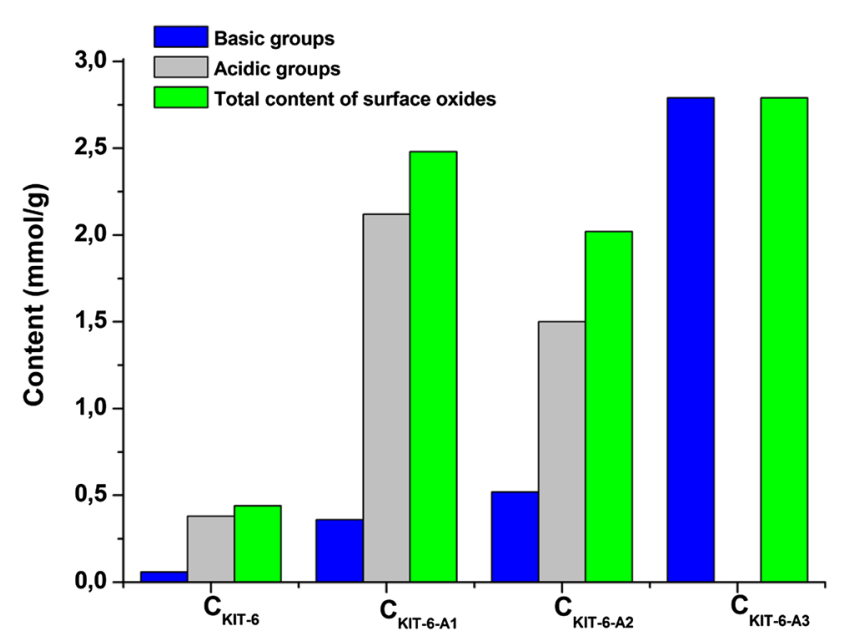

Fig. 4 Acid-base properties of pristine and functionalized mesoporous carbons

in time $\mathrm{t}(\mathrm{mg} / \mathrm{g}), t$ is the time ( $\mathrm{min}), k_{1}$ is the adsorption rate constant of pseudo-first order kinetics (1/min). For adsorption of 2,4-D herbicide the values of $k_{1}$ were found from the plots of $\ln \left(q_{e}-q_{t}\right)$ on $t$ (Fig. 6a).

A linear form of pseudo-second-order kinetic model of Ho and McKay was expressed by equation (Ho and McKay 1999):

$\frac{t}{q_{t}}=\frac{1}{k_{2} q_{e}{ }^{2}}+\frac{t}{q_{e}}$

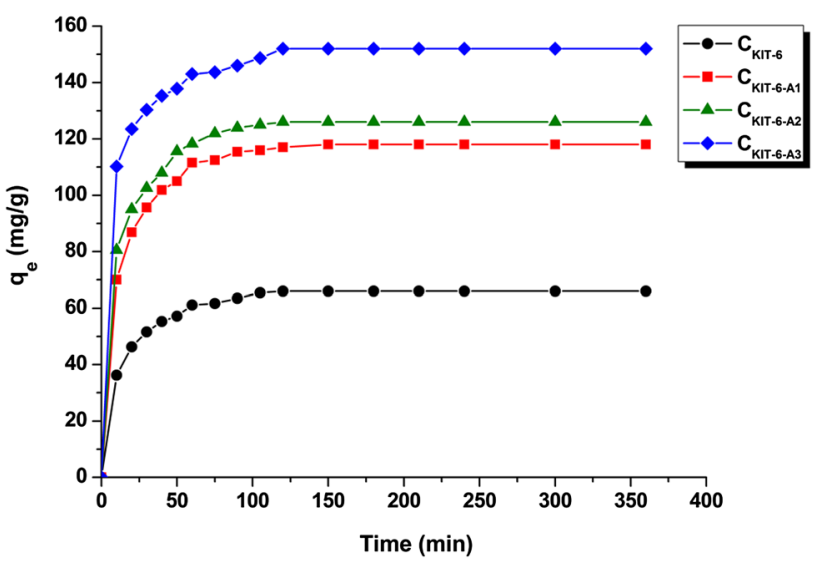

Fig. 5 Influence of contact time on the amount of 2,4-D adsorbed onto mesoporous carbons

where $k_{2}$ is the adsorption rate constant of pseudo-second order kinetics $(\mathrm{g} / \mathrm{mg} / \mathrm{min})$. The values $k_{2}$ were found from the plots of $t / q_{t}$ on $t$ (Fig. 6b).

The values of the constants $k_{1}, k_{2}$, correlation coefficients $\left(\mathrm{R}^{2}\right)$ and the calculated values of adsorbed 2,4-D $\left(q_{\text {e(cal })}\right)$ are given in Table 1 . Much higher values of $\mathrm{R}^{2}$ were obtained for the pseudo-second-order kinetic model, so this model better describes the herbicide adsorption $\left(\mathrm{R}^{2} \sim 0.999\right)$ than the Lagergren model. The values of $\mathrm{R}^{2}$ for the pseudo-firstorder kinetic are much lower (0.918-0.987). Moreover, the 

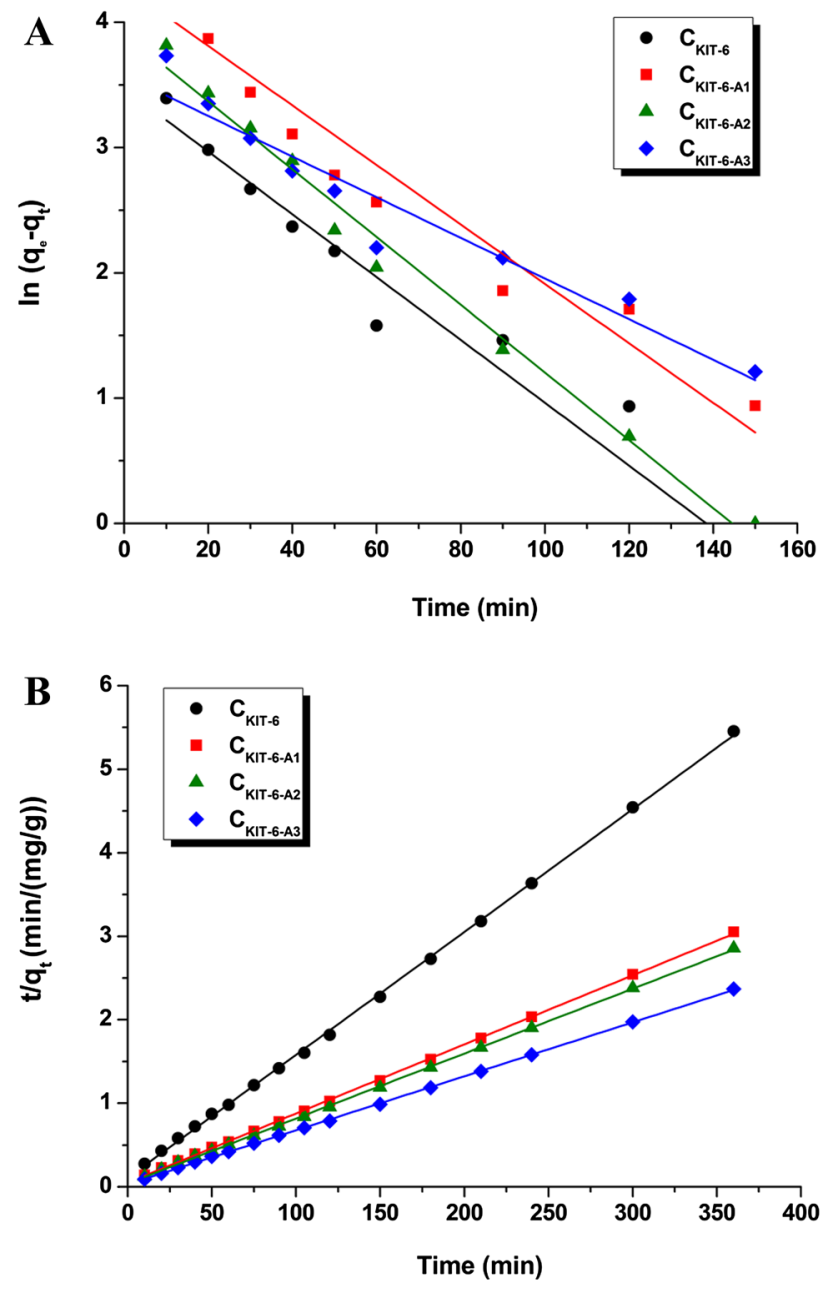

Fig. 6 Pseudo-first-order (A) and pseudo-second-order (B) kinetic plots for adsorption of herbicide onto mesoporous carbons (initial solution concentration of 2,4-D-100 mg/l)

experimental values of $q_{e}$ are closer to $q_{c a l}$ calculated on the basis of the pseudo-second-order model (Table 1).

The $\mathrm{pH}$ of aqueous solutions has an important role that influences uptake of adsorbate by mesoporous carbons. The adsorption performance of 2,4-D herbicide on the samples $\mathrm{C}_{\mathrm{KIT}-6}, \mathrm{C}_{\mathrm{KIT}-6-\mathrm{A} 1}, \mathrm{C}_{\mathrm{KIT}-6-\mathrm{A} 2}, \mathrm{C}_{\mathrm{KIT}-6-\mathrm{A} 3}$ as a function of $\mathrm{pH}$ was investigated in the range of $2-11$, and the results are presented in Fig. 7. It was found that removal of 2,4-D by carbon adsorbents at the initial stage increased with an increase in $\mathrm{pH}$ from 2 to 3 , then remained almost unaffected up to $\mathrm{pH}$ of 5. Further increase of $\mathrm{pH}$ in the range from 7 to 11 led to a decrease in sorption capacity of materials towards 2,4D. Because of low pKa value (2.73) of herbicide, it exists predominantly in anionic form (Bartczak et al. 2016; Koner et al. 2013). In acidic solutions the aminosilane-grafted mesoporous carbons become more positively charged which results in greater adsorption of anionic species.

The effectiveness of adsorption process is significantly influenced by the initial concentration of 2,4-D. Figure 8 presents the equilibrium adsorption isotherms of anionic herbicide onto aminosilane-grafted mesoporous carbons in aqueous solution. The adsorption is measured in milligrams of 2,4-D per a gram of adsorbent. For all samples the adsorbed amount of herbicide increases with increasing initial concentration until the plateau is reached. A higher initial 2,4-D concentration led to an increase in the mass gradient between the aqueous solution and the carbon materials, which then functions as a driving force for the transfer of herbicide molecules from the bulk solution to the adsorbents surface.

According to Fig. 8, the maximum sorption capacities of the mesoporous carbons are in the range $109-191 \mathrm{mg} / \mathrm{g}$. As follows from analysis, much more effective adsorbents of 2,4-D are the samples grafted with 3-aminopropyltriethoxysilane than pristine carbon $\mathrm{C}_{\mathrm{KIT}-6}$. It can be concluded that basic functional groups present on the surface of $\mathrm{C}_{\mathrm{KIT}-6-\mathrm{A} 1}, \mathrm{C}_{\mathrm{KIT}-6-\mathrm{A} 2}$ and $\mathrm{C}_{\mathrm{KIT}-6-\mathrm{A} 3}$ enhance the interaction between the carbon materials and the anionic herbicide.

The adsorption isotherms were fitted to the two models proposed by Langmuir and Freundlich. The Langmuir adsorption isotherm is described by the following linear equation (Langmuir 1918):

$\frac{C_{e}}{q_{e}}=\frac{1}{q_{m} K_{L}}+\frac{C_{e}}{q_{m}}$

where $q_{e}$ is the experimentally determined amount of the 2,4-D herbicide adsorbed on the samples $(\mathrm{mg} / \mathrm{g}), q_{m}$ is the theoretically predicted amount of adsorbed 2,4-D herbicide $(\mathrm{mg} / \mathrm{g}), C_{e}$ is the equilibrium concentration of the 2,4-D solution $(\mathrm{mg} / \mathrm{l}), K_{L}$ is the Langmuir constant. The parameters were computed from the intercept and linear gradient of the graphs of $C_{e} / q_{e}$ and $C_{e}$ (Fig. 9a).
Table 1 Parameters of pseudofirst-order and pseudo-secondorder kinetic models for adsorption of 2,4-D herbicide onto mesoporous carbons

\begin{tabular}{|c|c|c|c|c|c|c|c|}
\hline \multirow[t]{2}{*}{ Material } & \multirow[t]{2}{*}{$\mathrm{q}_{\mathrm{e}(\exp )}(\mathrm{mg} / \mathrm{g})$} & \multicolumn{3}{|c|}{ Pseudo-first-order model } & \multicolumn{3}{|c|}{ Pseudo-second-order model } \\
\hline & & $\mathrm{q}_{\mathrm{e}(\mathrm{cal})}(\mathrm{mg} / \mathrm{g})$ & $\mathrm{k}_{1}(1 / \min )$ & $\mathrm{R}^{2}$ & $\mathrm{q}_{\mathrm{e}(\mathrm{cal})}(\mathrm{mg} / \mathrm{g})$ & $\mathrm{k}_{2}(\mathrm{~g} / \mathrm{mg} / \mathrm{min})$ & $\mathrm{R}^{2}$ \\
\hline $\mathrm{C}_{\mathrm{KIT}-6}$ & 66 & 32 & 0.0578 & 0.950 & 68 & 0.0020 & 0.999 \\
\hline $\mathrm{C}_{\mathrm{KIT}-6-\mathrm{A} 1}$ & 118 & 65 & 0.0493 & 0.918 & 120 & 0.0014 & 0.999 \\
\hline $\mathrm{C}_{\mathrm{KIT}-6-\mathrm{A} 2}$ & 126 & 50 & 0.0621 & 0.987 & 128 & 0.0015 & 0.999 \\
\hline $\mathrm{C}_{\mathrm{KIT}-6-\mathrm{A} 3}$ & 152 & 40 & 0.0426 & 0.948 & 154 & 0.0014 & 0.999 \\
\hline
\end{tabular}




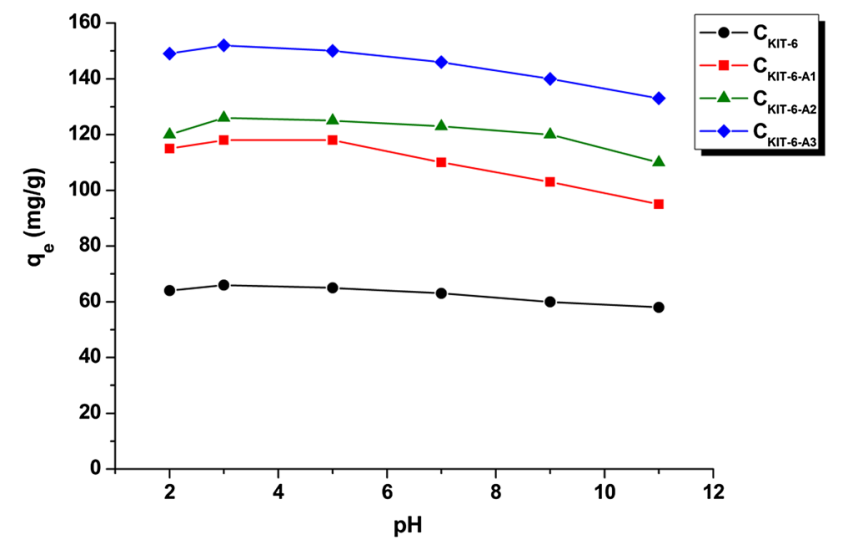

Fig. 7 Effect of $\mathrm{pH}$ on the removal of 2,4-D herbicide by aminosilane-functionalized mesoporous carbons (initial solution concentration of 2,4-D-100 mg/l)

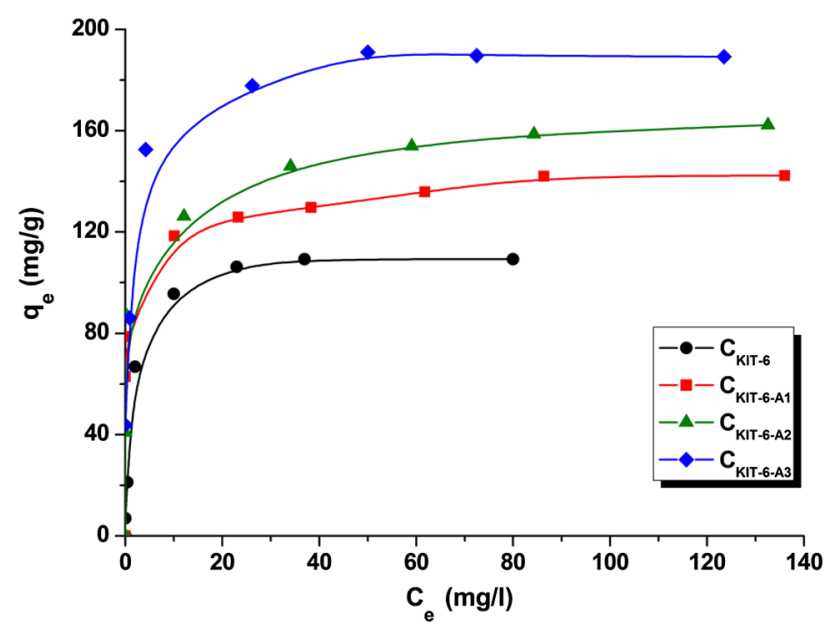

Fig. 8 Adsorption isotherms of 2,4-D herbicide onto mesoporous carbons

The linear form of Freundlich isotherm equation is expressed as (Freundlich 1906):

$\ln \mathrm{q}_{\mathrm{e}}=\ln \mathrm{K}_{\mathrm{F}}+1 / \mathrm{n} \ln \mathrm{C}_{\mathrm{e}}$

where $q_{e}$ is the experimentally determined amount of the 2,4-D herbicide adsorbed on the samples $(\mathrm{mg} / \mathrm{g}), C_{e}$ is the equilibrium concentration of the 2,4-D herbicide solution $(\mathrm{mg} / \mathrm{l}), K_{F}$ and $1 / n$ is the Freundlich constants, characteristic of a given system. The value of $1 / \mathrm{n}$ (varying from 0 to 1 ) is a measure of the intensity of adsorption or heterogeneity of the surface. The closer it is to zero, the more heterogeneous the surface. The plots of $\ln q_{e}$ versus $\ln C_{e}$ are shown in Fig. $9 b$.

The calculated parameters of the Langmuir and Freundlich isotherms based on the experimental data are collected in Table 2. The results indicate that the experimental
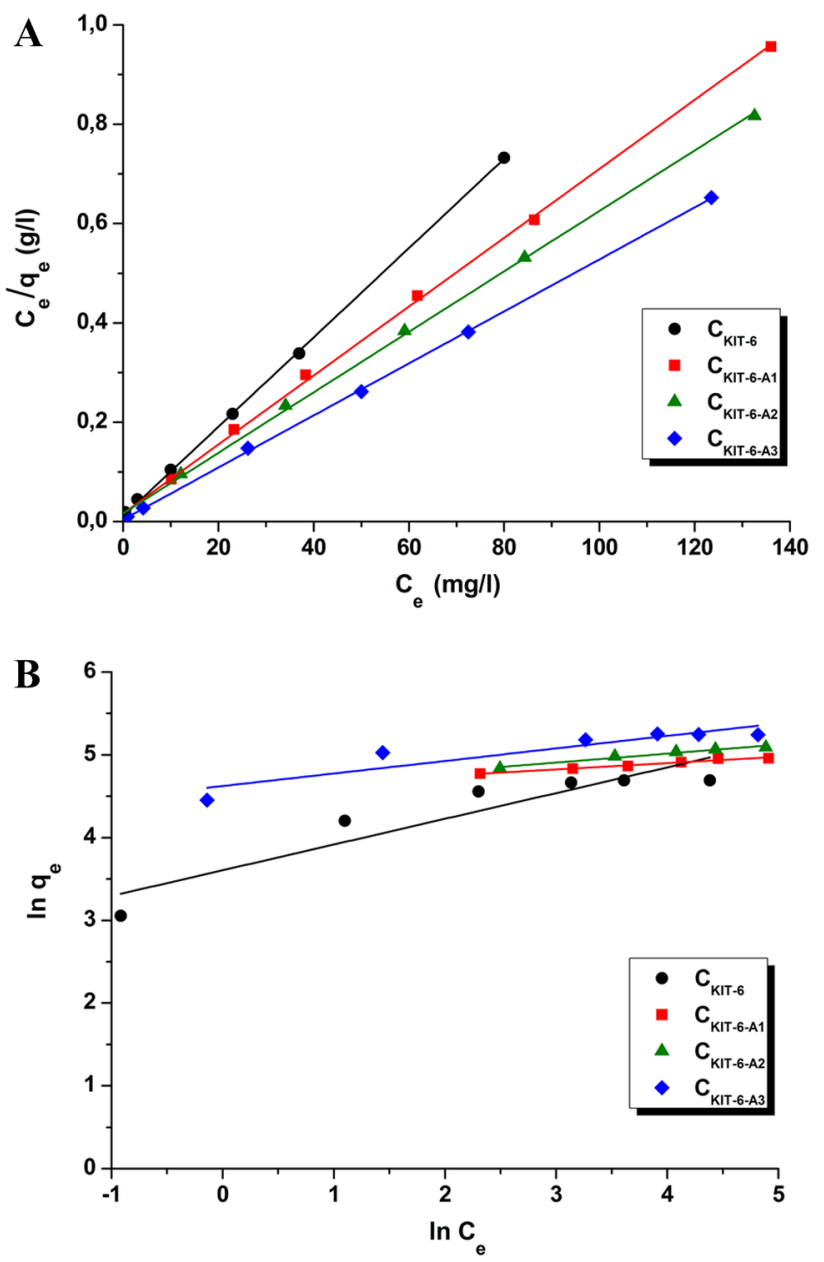

Fig. 9 Fit of experimental data concerning adsorption of 2,4-D herbicide onto mesoporous carbons, to the Langmuir (A) and Freundlich (B) models

data could be better described by Langmuir model than the Freundlich model in terms of higher $\mathrm{R}^{2}$ values. Therefore, the 2,4-D molecules were adsorbed on the surface of carbon materials via monolayer adsorption in homogeneous adsorption sites. Moreover, it should be mentioned that the experimental values of maximum adsorption capacities $\left(q_{e}\right)$ are close to the theoretical value of the maximum adsorption capacity $\left(q_{m}\right)$ calculated with the use Langmuir model.

The effect of temperature on the sorption capacity of aminosilane-grafted mesoporous carbons towards 2,4-D was also studied. According to the results, presented in Fig. 10, with temperature increasing from 25 to $60{ }^{\circ} \mathrm{C}$, the amount of adsorbed anionic herbicide slightly increased. It can be related to greater mobility of the $2,4-\mathrm{D}$ molecules in the aqueous solution. Within the porous structure of the carbon adsorbents the barrier of activation energy is overcome, which leads to the increase in the amount of the adsorbed herbicide. 
Table 2 Summary of parameters calculated from fitting the results of adsorption isotherms of 2,4-D herbicide onto mesoporous carbons to different models

\begin{tabular}{|c|c|c|c|c|c|c|c|}
\hline \multirow[t]{2}{*}{ Material } & \multirow[t]{2}{*}{$\mathrm{q}_{\mathrm{e}(\exp )}(\mathrm{mg} / \mathrm{g})$} & \multicolumn{3}{|l|}{ Langmuir } & \multicolumn{3}{|l|}{ Freundlich } \\
\hline & & $\mathrm{q}_{\mathrm{m}}(\mathrm{mg} / \mathrm{g})$ & $\mathrm{K}_{\mathrm{L}}(\mathrm{l} / \mathrm{mg})$ & $\mathrm{R}^{2}$ & $\begin{array}{l}\mathrm{K}_{\mathrm{F}}(\mathrm{mg} / \mathrm{g} \\
\left.(1 / \mathrm{mg})^{1 / \mathrm{n}}\right)\end{array}$ & $1 / \mathrm{n}$ & $\mathrm{R}^{2}$ \\
\hline $\mathrm{C}_{\mathrm{KIT}-6}$ & 109 & 110 & 0.67 & 0.999 & 36.82 & 0.31 & 0.866 \\
\hline $\mathrm{C}_{\mathrm{KIT}-6-\mathrm{A} 1}$ & 142 & 143 & 0.70 & 0.999 & 99.09 & 0.08 & 0.975 \\
\hline $\mathrm{C}_{\mathrm{KIT}-6-\mathrm{A} 2}$ & 161 & 162 & 0.87 & 0.999 & 98.10 & 0.11 & 0.969 \\
\hline $\mathrm{C}_{\mathrm{KIT}-6-\mathrm{A} 3}$ & 191 & 192 & 1.27 & 0.999 & 101.95 & 0.15 & 0.846 \\
\hline
\end{tabular}

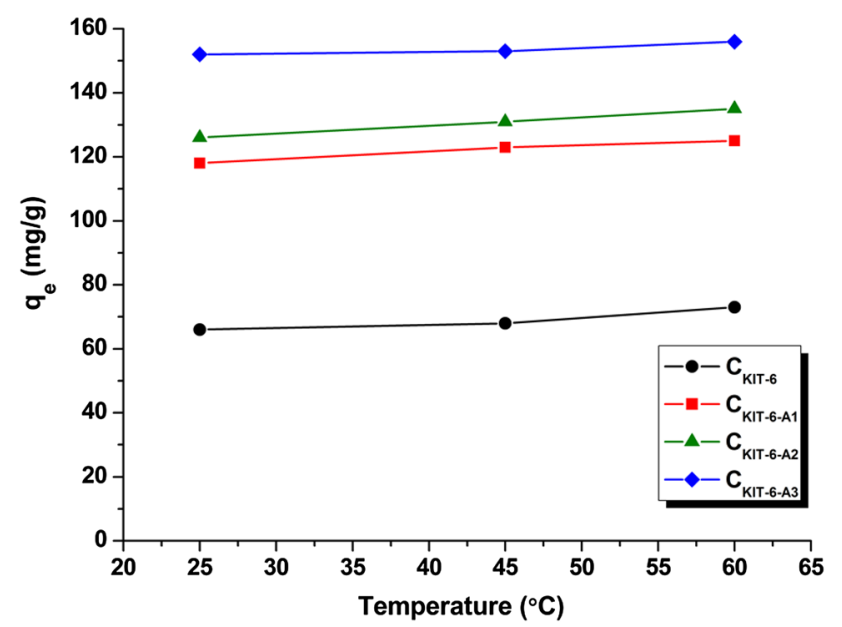

Fig. 10 Effect of temperature on the removal of 2,4-D herbicide by aminosilane-functionalized mesoporous carbons (initial solution concentration of 2,4-D-100 mg/l)

Table 3 Thermodynamic parameters for the adsorption of 2,4-D herbicide onto mesoporous carbons

\begin{tabular}{lllll}
\hline Material & $\begin{array}{l}\text { Temperature } \\
\left({ }^{\circ} \mathrm{C}\right)\end{array}$ & $\begin{array}{l}\Delta \mathrm{G}^{\circ} \\
(\mathrm{kJ} / \mathrm{mol})\end{array}$ & $\begin{array}{l}\Delta \mathrm{H}^{\circ} \\
(\mathrm{kJ} / \mathrm{mol})\end{array}$ & $\begin{array}{l}\Delta \mathrm{S}^{\circ} \\
(\mathrm{J} / \mathrm{Kmol})\end{array}$ \\
\hline $\mathrm{C}_{\text {KIT-6 }}$ & 25 & -16.85 & 3.06 & 66.69 \\
& 45 & -18.08 & & \\
& 60 & -19.20 & & \\
$\mathrm{C}_{\text {KIT-6-A1 }}$ & 25 & -19.09 & 3.34 & 73.39 \\
& 45 & -20.59 & & \\
& 60 & -21.66 & & \\
$\mathrm{C}_{\text {KIT-6-A2 }}$ & 25 & -19.43 & 2.76 & 76.39 \\
& 45 & -20.95 & & \\
& 60 & -22.11 & & \\
$\mathrm{C}_{\text {KIT-6-A3 }}$ & 25 & -20.48 & 1.48 & 73.65 \\
& 45 & -21.91 & & \\
& 60 & -23.07 & & \\
\hline
\end{tabular}

Table 3 presents the values of the three thermodynamic parameters $\left(\Delta \mathrm{G}^{\circ}, \Delta \mathrm{H}^{\circ}, \Delta \mathrm{S}^{\circ}\right)$ for the sorption of 2,4-D. The values of $\Delta \mathrm{G}^{\circ}$ (Gibbs free energy change) for each temperature were calculated taking into account the dimensionless constant $\mathrm{K}_{\mathrm{C}}$, from the following thermodynamic equation:

$\Delta \mathrm{G}^{\circ}=-\mathrm{RT} \ln \mathrm{K}_{\mathrm{C}}$

where $\mathrm{R}$ is the universal gas constant $(8.314(\mathrm{~J} / \mathrm{K} \mathrm{mol})), \mathrm{T}$ is the absolute temperature $(\mathrm{K})$, and $\mathrm{K}_{\mathrm{C}}$ is the adsorption constant (Bartczak et al. 2016; Koner et al. 2013; Gupta et al. 2016).

In order to determine the changes in enthalpy $\left(\Delta \mathrm{H}^{\circ}\right)$ and entropy $\left(\Delta S^{\circ}\right)$, the plots of $\ln \mathrm{K}_{\mathrm{C}}$ on $1 / \mathrm{T}$ were made using the following equation (Verma et al. 2017):

$\ln \mathrm{K}_{\mathrm{C}}=\frac{\Delta S}{\mathrm{R}}-\frac{\Delta H}{\mathrm{RT}}$

The positive values of $\Delta \mathrm{H}^{\circ}$ (in the range 1.48-3.34 kJ/ mol) obtained for all samples suggest that the 2,4-D adsorption is of endothermic nature, while the negative values of $\Delta \mathrm{G}^{\circ}$ imply that it is a spontaneous process. When temperature is increased from 25 to $60{ }^{\circ} \mathrm{C}, \Delta \mathrm{G}^{\circ}$ decreases, so the degree of spontaneity of the thermodynamic reaction increases. The values of entropy vary in the range 66.69-76.39 J/K mol (Table 3).

Thus far, numerous adsorbents have been applied for 2,4-D removal from aqueous solutions. A comparison of literature sorption capacities of different materials towards 2,4-D herbicide is presented in Table 4. Aminosilane-grafted mesoporous carbons are more effective adsorbents of 2,4-D than powdered activated carbons (Aksu and Kabasakal 2004), Cladium mariscus (Bartczak et al. 2016), chitosan (Harmoudi et al. 2014), chitin (Harmoudi et al. 2014), blast furnace sludge (Gupta et al. 2006), blast furnace dust (Gupta et al. 2006) or modified silica gel (Koner et al. 2013). This high adsorption capacity could be ascribed to the unique properties of carbon materials obtained (Goscianska and Olejnik 2018). The samples modified with APTES have good dispersibility in water solutions due to the presence of organic functional groups on their surface. Therefore, the diffusion resistance between adsorbents and 2,4-D molecules could be reduced. 
Table 4 Comparison of the adsorption capacity of mesoporous carbons towards 2,4-D herbicide with various adsorbents

\begin{tabular}{lll}
\hline Adsorbent & $\begin{array}{l}\text { Sorption capacities } \\
(\mathrm{mg} / \mathrm{g})\end{array}$ & References \\
\hline Cladium mariscus & 65.58 & Bartczak et al. (2016) \\
Chitosan & 11.0 & Harmoudi et al. (2014) \\
Chitin & 6.0 & Harmoudi et al. (2014) \\
Powdered activated carbon & 97.4 & Aksu and Kabasakal (2004) \\
Commercial activated carbon (AC F400) & $8.13-10.48$ & Son Tran et al. (2015) \\
Modified silica gel & 17.7 & Koner et al. (2013) \\
Blast furnace sludge & 30.0 & Gupta et al. (2006) \\
Blast furnace dust & 21.0 & Gupta et al. (2006) \\
Mesoporous carbon C & 109.0 & This study \\
Aminosilane-grafted mesoporous carbons & $142.0-191.0$ & This study \\
\hline
\end{tabular}

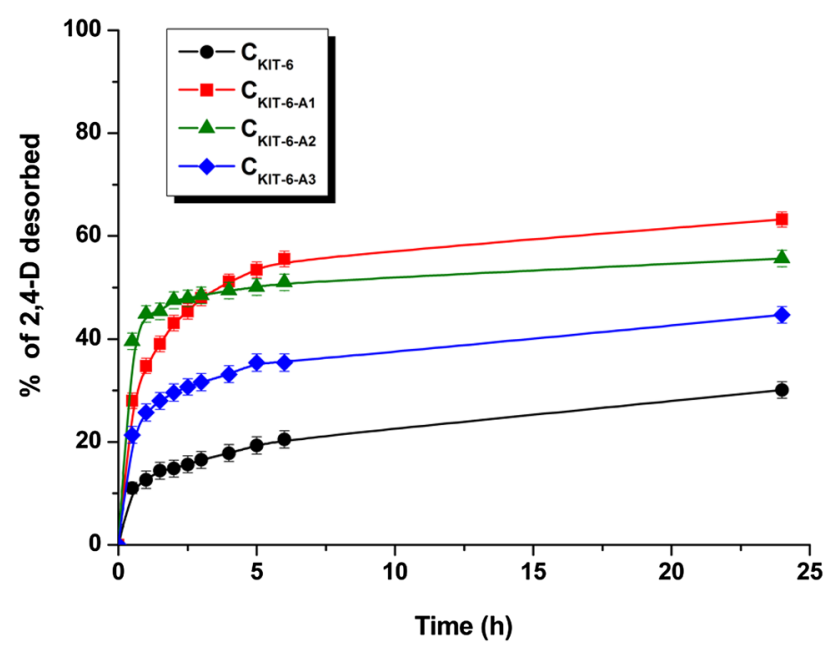

Fig. 11 2,4-D herbicide desorption curves for pristine and functionalized mesoporous carbons in distilled water

\subsection{Desorption studies}

It can be seen in Fig. 11 that functionalization of mesoporous carbon material has an influence on the desorption process of herbicide. After $24 \mathrm{~h}$ the percentage of desorbed 2,4-D from mesoporous carbons was as follows $30 \%\left(\mathrm{C}_{\mathrm{KIT}-6}\right)$, $45 \%\left(\mathrm{C}_{\mathrm{KIT}-6-\mathrm{A} 3}\right), 56 \%\left(\mathrm{C}_{\mathrm{KIT}-6-\mathrm{A} 2}\right), 63 \%\left(\mathrm{C}_{\mathrm{KIT}-6-\mathrm{A} 1}\right)$. This pattern may be related to the sorption strength of the herbicide on the carbon materials. Much lower amount of 2,4-D was desorbed from non-functionalized mesoporous carbon than from the modified materials. We suggest that the 2,4-D molecules were loaded inside the pores of $\mathrm{C}_{\mathrm{KIT}-6}$ and therefore they could not be easily desorbed to receptor medium. The modification of mesoporous carbon surface changed the sorption-desorption properties towards 2,4-D. Moreover, the amount of basic and acidic groups on the surface may influence the yield of herbicide's desorption. The amount of 2,4-D desorbed from functionalized materials decreased when higher amount of basic groups were loaded on the surface of mesoporous carbons. According to Aquino et al. (2007) the molecules of 2,4-D can interact via hydrogen bonds with different functional groups in polar solvents. The mechanism of 2,4-D adsorption could be also based on electrostatic interactions between the negatively charged herbicide and positively charged aminosilane-grafted mesoporous carbon. Furthermore, van der Waals forces could also contribute to interactions between 2,4-D and aminosilanegrafted mesoporous carbons. Depending on the strength of hydrogen bonds, van der Walls forces and electrostatic interactions, that act simultaneously, the desorption profiles were different. It is assumed that one fraction of 2,4-D molecules was located on the outer surface of the material. The total amount of 2,4-D was not desorbed in any case therefore we suggest that the second fraction of herbicide molecules might be located inside the pores of the carbon materials or may interact with their walls.

The mechanism of 2,4-D desorption from mesoporous carbon materials was explained by fitting the results with five different kinetics models. For all aminosilane-grafted mesoporus carbons the highest values of regression coefficient was observed for the Korsmeyer-Peppas model (Table 5). This suggests that the desorption of 2,4-D from $\mathrm{C}_{\mathrm{KIT}-6-\mathrm{A} 1,} \mathrm{C}_{\mathrm{KIT}-6-\mathrm{A} 2,} \mathrm{C}_{\mathrm{KIT}-6-\mathrm{A} 3}$ followed this kinetics equation. The $n$ values of all these materials were below 0.5 that indicates the Fickian diffusion mechanism. However, for pristine material the highest regression coefficient was calculated for the Higuchi model, which implies that the desorption of 2,4-D involved diffusion process.

\section{Conclusion}

Ordered mesoporous carbon of cubic structure has been subjected to surface oxidation followed by functionalization with different amounts of 3-aminopropyltriethoxysilane. Aminosilane-grafted materials show smaller surface areas and total pore volumes but greater average pore 
Table 5 Kinetics models used to describe 2,4-D desorption from mesoporous carbon materials

\begin{tabular}{lllllll}
\hline Material & Zero order & First order & Higuchi model & $\begin{array}{l}\text { Hixson-Crowell } \\
\text { model }\end{array}$ & $\begin{array}{l}\text { Korsmeyer- } \\
\text { Peppas model }\end{array}$ & $\mathrm{n}$ \\
\hline $\mathrm{C}_{\text {KIT-6 }}$ & 0.966 & 0.974 & 0.999 & 0.972 & 0.995 & 0.286 \\
$\mathrm{C}_{\text {KIT-6-A1 }}$ & 0.862 & 0.914 & 0.954 & 0.899 & 0.987 & 0.236 \\
$\mathrm{C}_{\text {KIT-6-A2 }}$ & 0.915 & 0.929 & 0.982 & 0.925 & 0.999 & 0.073 \\
$\mathrm{C}_{\text {KIT-6-A3 }}$ & 0.915 & 0.932 & 0.981 & 0.927 & 0.996 & 0.172 \\
\hline
\end{tabular}

diameter than the unmodified sample. The modification of mesoporous carbon with APTES leads to generation of basic functional groups on its surface.

According to the results obtained, the most effective adsorbent of 2,4-D from water solutions is the material $\mathrm{C}_{\mathrm{KIT}-6-\mathrm{A} 3}$ whose surface shows the most basic character of all samples studied. The presence of amine groups on the carbon surface increases its sorption capacity towards the 2,4-D herbicide. The isotherms of 2,4-D adsorption, recorded for all samples studied, have been established to be of Langmuir type. The kinetics of herbicide adsorption on the aminosilane-grafted mesoporous carbons were better described by the pseudo-second-order model. With temperature increased from 25 to $60{ }^{\circ} \mathrm{C}$, the sorption capacities of the materials studied towards 2,4-D increased. The process of 2,4-D adsorption was found to be endothermic and of spontaneous character as indicated by the positive values of $\Delta \mathrm{H}$ and negative values of $\Delta \mathrm{G}$. According to the results obtained, the herbicide sorption was more effective in an acidic environment. The desorption efficiency was strongly affected by the amount of basic and acidic groups on the surface of functionalized carbons. It was observed that with increase in the amount of basic groups decreased the ability of 2,4-D to be desorbed from materials obtained.

Acknowledgements Financial support from Polish Ministry of Science and Higher Education is acknowledged.

Open Access This article is distributed under the terms of the Creative Commons Attribution 4.0 International License (http://creativeco mmons.org/licenses/by/4.0/), which permits unrestricted use, distribution, and reproduction in any medium, provided you give appropriate credit to the original author(s) and the source, provide a link to the Creative Commons license, and indicate if changes were made.

\section{References}

Agarwal, S., Sadeghi, N., Tyagi, I., Gupta, V.K., Fakhri, A.: Adsorption of toxic carbamate pesticide oxamyl from liquid phase by newly synthesized and characterized grapheme quantum dots nanomaterials. J. Colloid Interface Sci. 478, 430-438 (2016)

Aksu, Z., Kabasakal, E.: Batch adsorption of 2,4-dichlorophenoxyacetic acid $(2,4-D)$ from aqueous solution by granular activated carbon. Sep. Purif. Technol. 35, 223-240 (2004)
Aquino, A.J.A., Tunega, D., Haberhauer, G., Gerzabek, M.H., Lischka, H.: Interaction of the 2,4-dichlorophenoxyacetic acid herbicide with soil organic matter moieties: a theoretical study. Eur. J. Soil. Sci. 58, 889-899 (2007)

Barczak, M., Michalak-Zwierz, K., Gdula, K., Tyszczuk-Rotko, K., Dobrowolski, R., Dąbrowski, A.: Ordered mesoporous carbons as effective sorbents for removal of heavy metal ions. Microporous. Mesoporous. Mater. 211, 162-173 (2015)

Bartczak, P., Żółtowska, S., Norman, M., Klapiszewski, Ł, Zdarta, J., Komosa, A., Kitowski, I., Ciesielczyk, F., Jesionowski, T.: Sawsedge Cladium mariscus as functional low-cost adsorbent for effective removal of 2,4-dichlorophenoxyacetic acid from aqueous systems. Adsorption 22, 517-529 (2016)

Boehm, H.P.: Some aspects of the surface chemistry of carbon blacks and other carbons. Carbon 32, 759-769 (1994)

Bradberry, S.M., Proudfoot, A.T., Vale, J.A.: Poisoning due to chlorophenoxy herbicides. Toxicol. Rev. 23, 65-73 (2004)

Broseus, R., Vincent, S., Aboulfadl, K., Daneshvar, A., Sauve, S., Barbeau, B., Prevost, M.: Ozone oxidation of pharmaceuticals, endocrine disruptors and pesticides during water treatment. Water Res. 43, 4707-4717 (2009)

Bus, J.S., Hammond, L.E.: Regulatory progress, toxicology, and public concerns with 2,4-D: where do we stand after two decades? Crop Prot. 26, 266-269 (2007)

Dash, S., Murthy, P.M., Nath, L., Chowdhury, P.: Kinetic modeling on drug release from controlled drug delivery systems. Acta Pol. Pharm. 67, 217-223 (2010)

Freundlich, H.M.F.: Over the adsorption in solution. J. Phys. Chem. 57, 385-470 (1906)

Goscianska, J., Olejnik, A.: Dispersion stability of the aminosilanegrafted mesoporous carbons in different solvents. Microporous Mesoporous Mater. 265, 149-161 (2018)

Goscianska, J., Olejnik, A., Pietrzak, R.: Adsorption of 1-phenylalanine onto mesoporous silica. Mater. Chem. Phys. 142, 586-593 (2013)

Goscianska, J., Olejnik, A., Nowak, I.: Sorptive properties of aluminium ions containing mesoporous silica towards L-histidine. Adsorption 22, 571-579 (2016a)

Goscianska, J., Olejnik, A., Nowak, I., Marciniak, M., Pietrzak, R.: Stability analysis of functionalized mesoporous carbon materials in aqueous solution. Chem. Eng. J. 290, 209-219 (2016b)

Goscianska, J., Fathy, N.A., Aboelenin, R.M.M.: Adsorption of solophenyl red 3BL polyazo dye onto amine-functionalized mesoporous carbons. J. Colloid Interface Sci. 505, 593-604 (2017)

Gupta, V.K., Ali, I., Saini, V.K.: Adsorption of 2,4-D and carbofuran pesticides using fertilizer and steel industry wastes. J. Colloid Interface Sci. 299, 556-563 (2006)

Gupta, V.K., Chandra, R., Tyagi, I., Verma, M.: Removal of hexavalent chromium ions using $\mathrm{CuO}$ nanoparticles for water purification application. J. Colloid Interface Sci. 478, 54-62 (2016)

Harmoudi, H.El., Gaini, L.El., Daoudi, E., Rhazi, M., Boughaleb, Y., Mhammedi, M.A.El., Migalska-Zalas, A., Bakasse, M.: Removal of 2,4-D from aqueous solution by adsorption processing using 
two biopolymers: chitin and chitosan and their optical properties. Opt. Mater. 36, 1471-1477 (2014)

Ho, Y.S., McKay, G.: Pseudo-second order model for sorption processes. Process Biochem. 34, 451-465 (1999)

Koner, S., Pal, A., Adak, A.: Adsorption of 2,4-D herbicide from water environment on modified silica gel factory waste. Water Environ. Res. 85, 2147-2156 (2013)

Lagergren, S.: About the theory of so-called adsorption of soluble substances. Kungliga Svenska Vetensk. Handl. 24, 1-39 (1898)

Langmuir, I.: The adsorption of gases on plane surfaces of glass, mica and platinum. J. Am. Chem. Soc. 40, 1361-1403 (1918)

Li, J., Li, Y., Lu, J.: Adsorption of herbicides 2,4-D and acetochlor on inorganic-organic bentonites. Appl. Clay Sci. 46, 314-318 (2009)

Liu, W., Yang, Q., Yang, Z., Wang, W.: Adsorption of 2,4-D on magnetic graphene and mechanism study. Colloids Surf. A 509, 367-375 (2016)

Nethaji, S., Sivasamy, A.: Graphene oxide coated with porous iron oxide ribbons for 2,4-Dichlorophenoxyacetic acid (2,4-D) removal. Ecotoxicol. Environ. Saf. 138, 292-297 (2017)

Njoku, V.O., Hameed, B.H.: Preparation and characterization of activated carbon from corncob by chemical activation with $\mathrm{H}_{3} \mathrm{PO}_{4}$ for 2,4-dichlorophenoxyacetic acid adsorption. Chem. Eng. J. 173, 391-399 (2011)

Njoku, V.O., Asif, M., Hameed, B.H.: 2,4-Dichlorophenoxyacetic acid adsorption onto coconut shell-activated carbon: isotherm and kinetic modeling. Desalin. Water Treat. 55, 132-141 (2015)

Olejnik, A., Nowak, I., Schroeder, G.: Functionalized polystyrene beads as carriers in release studies of two herbicides: 2,4-dichlorophenoxyacetic acid and 2-methyl-4-chlorophenoxyacetic acid. Int. J. Environ. Sci. Technol. https://doi.org/10.1007/s13762-0182138-4 (2018a)

Olejnik, A., Glowka, A., Nowak, I.: Release studies of undecylenoyl phenylalanine from topical formulations. Saudi Pharm. J. 26, 709-718 (2018b)
Ormad, M.P., Miguel, N., Calvert, A., Matesanz, J.M., Obelleiro, J.L.: Pesticides removal in the process of drinking water production. Chemosphere 71, 97-106 (2008)

Ova, D., Ovex, B.: 2,4-Dichlorophenoxyacetic acid removal from aqueous solutions via adsorption in the presence of biological contamination. J. Environ. Chem. Eng. 1, 813-821 (2013)

Reigart, J.R., Roberts, J.R.: Chlorophenoxy Herbicides, recognition and management of pesticide poisonings, 5th edn., pp. 94-96. U.S. Environmental Protection Agency. Office of Prevention, Pesticides and Toxic Substances, Office of Pesticide Programs, U.S. Government Printing Office, Washington, DC (1999)

Sahoo, S., Chakraborti, C.K., Behera, P.K.: Development and evaluation of gastroretentive controlled release polymeric suspensions containing ciprofloxacin and carbopol polymers. J. Chem. Pharm. Res. 4, 2268-2284 (2012)

Son Tran, V., Ngo, H.H., Guo, W., Zhang, J., Liang, S., Ton-That, C., Zhang, X.: Typical low cost biosorbents for adsorptive removal of specific organic pollutants from water. Bioresour. Technol. 182, 353-363 (2015)

Tsogas, G.Z., Giokas, D.L., Nikolakopoulos, P.G., Vlessidis, A.G., Evmiridis, N.P.: Determination of the pesticide carbaryl and its photodegradation kinetics in natural waters by flow injectiondirect chemiluminescence detection. Anal. Chim. Acta 573-574, 354-359 (2006)

Verma, M., Tyagi, I., Chandra, R., Gupta, V.K.: Adsorptive removal of $\mathrm{Pb}$ (II) ions from aqueous solution using $\mathrm{CuO}$ nanoparticles synthesized by sputtering method. J. Mol. Liq. 225, 936-944 (2017)

Yang, Y., Wang, J., Qian, X., Shan, Y., Zhang, H.: Aminopropylfunctionalized mesoporous carbon (APTMS-CMK-3) as effective phosphate adsorbent. Appl. Surf. Sci. 427, 206-214 (2018) 